OPEN ACCESS

Edited by:

Alex Nicolas Gordon-Weeks, University of Oxford, United Kingdom

Reviewed by:

Carlo Ceresa,

University of Oxford, United Kingdom

Benedetto lelpo,

Parc de Salut Mar, Spain

*Correspondence:

Yanmei Zou

zouyanmei0101@126.com

Specialty section:

This article was submitted to

Surgical Oncology,

a section of the journal

Frontiers in Oncology

Received: 16 October 2020

Accepted: 17 February 2021

Published: 11 March 2021

Citation:

Chen $X$, Meng $F$, Xiong $H$ and Zou $Y$ (2021) Adjuvant Therapy for Resectable Biliary Tract Cancer: A

Bayesian Network Analysis.

Front. Oncol. 11:600027.

doi: 10.3389/fonc.2021.600027

\section{Adjuvant Therapy for Resectable Biliary Tract Cancer: A Bayesian Network Analysis}

\author{
Xiuqiong Chen ${ }^{1}$, Fanqiao $\mathrm{Meng}^{2}$, Hua Xiong ${ }^{1}$ and Yanmei Zou ${ }^{1 *}$ \\ ${ }^{1}$ Department of Oncology, Tongji Hospital, Tongji Medical College, Huazhong University of Science and Technology, Wuhan, \\ China, ${ }^{2}$ Department of Hematology, Tianjin Medical University General Hospital, Tianjin, China
}

Background: Selecting proper postoperative adjuvant therapy is of great importance for prolonging overall survival (OS) of patients with biliary tract cancer (BTC). OS is commonly affected by high rate of postoperative recurrence and metastasis.

Purpose: The present study aimed to identify the optimal adjuvant therapy for BTC patients.

Method: A comprehensive search was carried out on Pubmed, Web of science, and Embase databases to acquire articles regarding BTC therapy approaches. Subsequently, the hazard ratio (HR) and its 95\% confidence intervals (Cls) were applied to evaluate the efficacy of different adjuvant therapy regimens. The GemTc (GemTc.0.8-2) and R (R.3.6.0) software were employed to perform statistical analyses.

Result: Data from 22 articles, including 14,646 patients, were quantitatively analyzed. The results showed that in terms of 5-year OS, gemcitabine (GEM) was considered as the optimal adjuvant therapy for BTC compared with chemoradiotherapy (CRT; HR = 0.59; $95 \% \mathrm{Cl}=0.34-0.97$ ), observation (OB; $\mathrm{HR}=0.49 ; 95 \% \mathrm{Cl}=0.33-0.73$ ), and radiotherapy $(\mathrm{RT} ; \mathrm{HR}=0.40 ; 95 \% \mathrm{Cl}=0.22-0.71)$. Additionally, 5-fluorouracil (5-FU) exhibited improved efficacy compared with $\mathrm{RT}(\mathrm{HR}=0.52 ; 95 \% \mathrm{Cl}=0.29-0.91)$ and $\mathrm{OB}(\mathrm{HR}=0.63 ; 95 \% \mathrm{Cl}=0.43-0.92)$. When the efficacy of 5-FU was compared with that of GEM, the results showed that 5-FU $(H R=1.29)$ was more effective than GEM. Furthermore, CRT and RT prolonged positive resection margin $\left(\mathrm{R}^{+}\right)$-OS $(\mathrm{HR}=0.69 ; 95 \%$ $\mathrm{Cl}=0.49-1.00)$ and positive lymph node- $\left(\mathrm{N}^{+}\right)$-OS $(\mathrm{HR}=0.22 ; 95 \% \mathrm{Cl}=0.074-0.66)$ in BTC patients. In terms of median recurrence-free survival (RFS) and 1-year OS, the differences were not statistically significant among different therapeutic interventions.

Conclusion: The present study suggested that GEM could be used as a first-line adjuvant therapy for resected BTC patients. Additionally, CRT could be the optimal treatment approach for $\mathrm{R}^{+}$and $\mathrm{N}^{+}$patients.

Keywords: biliary tract cancer (BTC), adjuvant therapy (AT), gemcitabine, fluorouracil, chemo-radiotherapy, radiotherapy, observation 


\section{INTRODUCTION}

It is well-known that biliary tract cancer (BTC), including gallbladder carcinoma and cholangiocarcinoma, belongs to a collective category of cancers, which is an aggressive malignant tumor with increasing incidence worldwide, accounting for $\sim 3 \%$ of gastrointestinal tumor cases $(1,2)$. Like many other gastrointestinal tumors, the majority of BTC patients are diagnosed at an advanced stage, therefore, only $20 \%$ of BTC patients are eligible to undergo radical resection $(3,4)$. However, even after radical resection, the 1-year recurrence rate has been estimated to be $\sim 50 \%(4,5)$. Therefore, there is an imperative need for effective postoperative adjuvant therapies, including radiotherapy (RT), chemotherapy, and chemoradiotherapy (CRT), in order to prolong the overall survival (OS) and diseasefree survival (DFS) of BTC patients. Currently, several adjuvant therapy strategies have been developed, however, which type of adjuvant therapy offers the most optimal survival benefit remains still controversial.

Over the past decades, researchers around the world have attempted to develop an effective adjuvant therapy for BTC, however, no considerable progress has been achieved. Randomized controlled trials (RCTs) on BTC are still sparse, and this is especially true for studies on adjuvant therapy. However, some retrospective studies and review reports have confirmed the importance of adjuvant therapy. A meta-analysis, including 20 clinical trials, revealed that adjuvant therapy could not provide a survival benefit for patients with BTC, however, the benefits on positive lymph node $\left(\mathrm{N}^{+}\right)$and positive resection margin $\left(\mathrm{R}^{+}\right)$ disease status were confirmed (6). Another study suggested that gemcitabine (GEM) was the appropriate adjuvant therapy for BTC, with a tolerable toxicity, while concurrent CRT offered short-term survival benefits following tumor resection (7). Recently, several prospective trials have been published regarding adjuvant therapy for BTC, thus providing powerful evidence for treatment options. Two randomized phase III studies, each including 225 and 196 patients, investigated whether GEMbased therapy could result in significantly increased OS and recurrence-free survival (RFS) rates compared with surveillance only. No obvious benefits were observed in GEM-treated patients despite the good tolerance $(8,9)$. Furthermore, BILCAP study, a randomized, controlled, multicenter, phase III clinical trial, demonstrated that capecitabine, as adjuvant chemotherapy, exhibited beneficial effect on OS and a manageable safety profile in patients with resected BTC (10). In the present study, a Bayesian network meta-analysis was performed based on all eligible publications, in order to identify the optimal adjuvant therapy for BTC.

\section{MATERIALS AND METHODS}

\section{Literature Search Strategy}

In the present study, a systematic review of the English literature was performed on Pubmed, Web of Science, and EMBASE databases, until April 1, 2019, according to the Preferred Reporting Items for Systematic Reviews and Meta-Analyses (PRISMA) guidelines (11). The combinations of keywords used were as follows: "adjuvant treatment"; "adjuvant therapy"; "adjuvant chemoradiotherapy"; "adjuvant radiotherapy"; "adjuvant chemotherapy"; and "resected; "resectable"; and "cholangiocarcinoma"; "gallbladder cancer"; "biliary tract cancer"; "biliary cancer"; "bile duct cancer." The reference lists of previous meta-analyses and published articles from the initial search were also screened in order to avoid omission of relevant literatures.

\section{Inclusion Criteria}

The eligibility criteria were defined by the Population, Intervention, Comparison, Outcome, Study design (PICOS) framework (11). (i) Population: All postoperative studies, which defined patients as the target population. All patients were pathologically diagnosed with BTC; (ii) Intervention: Interventions included adjuvant CRT, adjuvant chemotherapy [5-fluorouracil (5-FU) and GEM], adjuvant RT and observation. Furthermore, at least 20 BTC patients were included in each intervention; (iii) Comparison: Each study was composed of at least two or more interventions and the comparison was performed between the interventions. (iv) Outcome: The main outcomes of interest included 1-year OS rate, 5-year OS rate, and median-RFS rate. Other data such as survival and recurrence were also available in the selected articles.

\section{Data Extraction and Quality Assessment}

Data were extracted from the selected literature by two investigators independently (FM and YLW). Data included author, year, treatment measures, patient number, design scheme, 1-year OS rate, 5-year OS rate, median-RFS rate, and the efficacy of adjuvant therapy on $\mathrm{N}^{+}$and $\mathrm{R}^{+}$patients. The kappa coefficient $(\kappa)$ was applied to evaluate the consistency of the data extracted by the two investigators (12). The SPSS software (SPSS 16.0) was used to calculate the $\kappa$ value, while $\kappa>0.5$ was considered to indicate a good consistency among data. If discrepancies emerged, a third investigator joined to resolve the disputes between the two investigators. If data from the extracted literatures were missing, the practical methods by Tierney et al. (13) and Parma et al. (14) were applied to analyze missing statistical variables. In addition, the Cochrane Collaboration's Risk of Bias (ROB) assessment tool was used to evaluate risk of bias and quality of RCTs (15), while the Newcastle-Ottawa Scale (NOS) was utilized to assess the quality and risk of bias of the non-RCTs $(16,17)$. Finally, the Grading of Recommendations Assessment, Development and Evaluation (GRADE) framework was used to assess the quality of evidence (18).

\section{Data Analysis Heterogeneity}

A pair-wise meta-analysis was performed to synthesize evidence from multiple studies with the same treatment regimen. When quantification of heterogeneity could not be performed, the fixedeffect or random-effect model was adopted. The Cochran's I square $\left(\mathrm{I}^{2}\right)$ and $\mathrm{Q}$ statistics were used to determine the percentage of heterogeneity among studies $(19,20)$. The $\mathrm{I}^{2}$ value was mainly used to describe heterogeneity, and a value $>50 \%$ was considered to indicate a statistically significant heterogeneity, suggesting 
that a subgroup analysis was required to identify the source of heterogeneity (21).

\section{Consistency and Inconsistency}

Unlike traditional meta-analysis, inconsistency in network metaanalysis refers to the similarity between direct and indirect results (22). Therefore, the node-splitting analysis in the $\mathrm{R}$ software was employed to calculate the inconsistency value between the direct and indirect results (23). A significant inconsistency was indicated when node-splitting analysis derived $P<0.05$ in the Bayesian network meta-analysis. Finally, when the inconsistency was not statistically significant, a consistency model was then employed.

\section{Network Meta-Analysis and Rank Probabilities}

HR for 1-year OS, 5-year OS, and median-RFS rate with its corresponding 95\% CI was used as the effect size estimate. To determine HRs and CIs, the number of deaths and sample size for each therapy from all studies were implemented into the GemTc software. When HR was $<1.0$ and a value $=1.0$ was not contained in the $95 \% \mathrm{CI}$, the results were statistically significant, indicating that the intervention of the experimental group was more effective compared with that of the control group. Furthermore, the ranking graphs of different outcomes were obtained. In the present study, the Brooks-Gelman-Rubin method was utilized to calculate the Potential Scale Reduction Factor (PSRF). PSRF represents the convergence degree by comparing the withinchain and between-chain variance. Therefore, a PSRF value
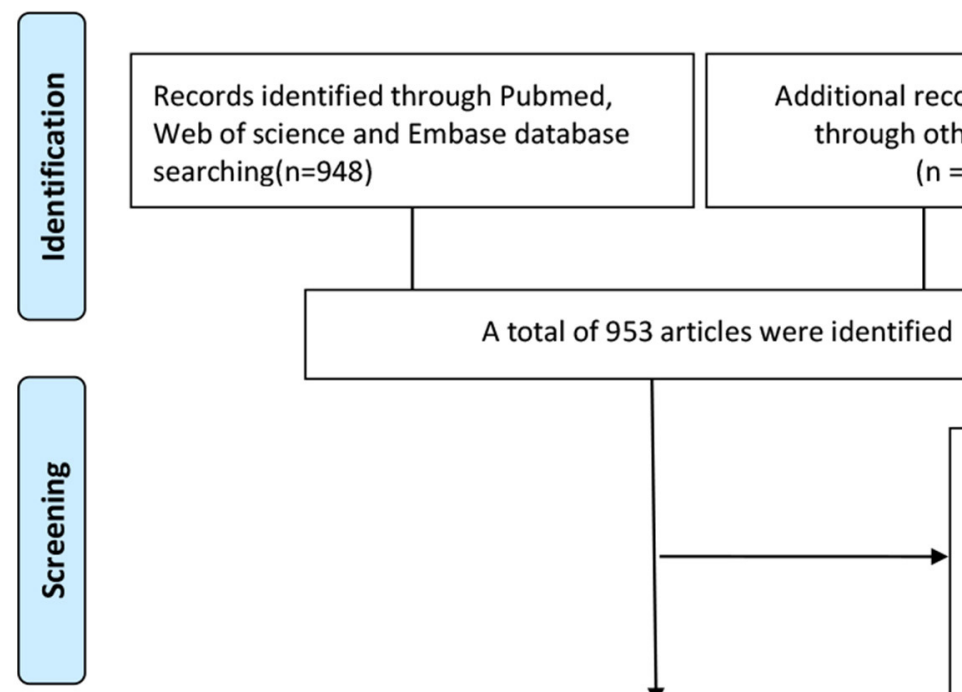

Duplicates excluded ( $n=384)$ and records excluded after browsing the title and abstract $(n=502)$ with following reasons:

1. Irrelevant literature $(n=408)$

2. Single-arm studies $(n=94)$

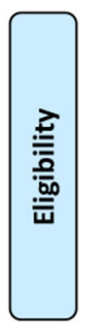

Full-text articles assessed for potentially eligibility $(n=67)$

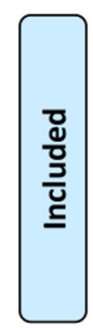

Studies included in qualitative synthesis $(n=22)$

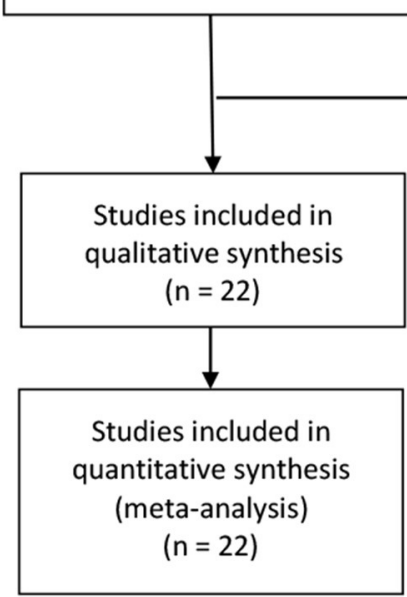

Full-text articles excluded, with following reasons:

1. No enough sufficient data( $n=24)$.

2. Insufficient sample size $(n=13)$. 3. The protocol for adjuvant therapy is unclear $(n=8)$

FIGURE 1 | Flow chart of literature screening. 
close or equal to 1.0 indicated that an optimal convergence was achieved. Additionally, the Markov chain Monte Carlo

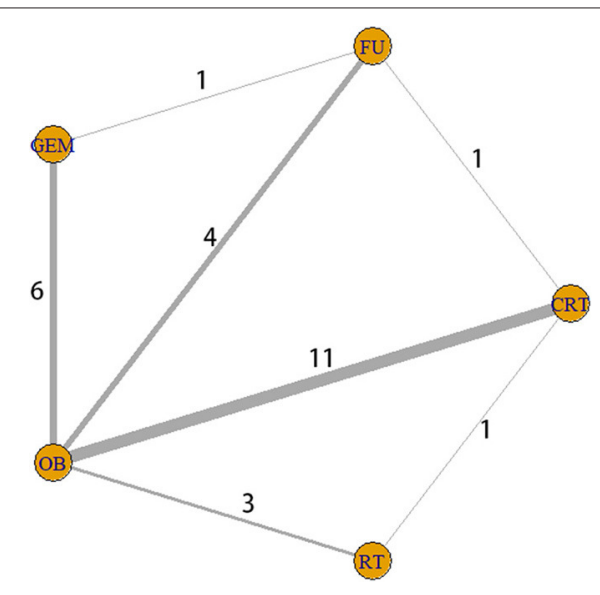

FIGURE 2 | Interaction network between interventions. The five yellow circles represent five different interventions, while the thickness of the lines connecting the circles is proportional to the number of trials.
(MCMC) method based on the Bayesian framework was applied for simulation analysis. Herein, four different chains were set, each producing 50,000 simulation iterations with a thinning rate of 10 . When 20,000 simulation iterations were completed, an optimal convergence degree was achieved $(24,25)$.

\section{RESULTS}

\section{Literature Features}

By searching different databases in detail, a total of 2,592 relevant articles were identified. Following check for duplicate articles, and preliminary screening of titles and abstracts, 2,525 references were excluded, and 67 potentially eligible literatures were assessed for full-text screening. Then, a total of 45 articles were excluded for the following reasons: insufficient data (24 articles); insufficient sample size (13 articles); and lack of detailed description of adjuvant therapy (8 articles). Finally, 22 articles with a total of 14,646 patients were selected for quantitative synthesis according to the filtering process shown in Figure 1. Patients with surgery alone accounted for $64.4 \%$ and adjuvant therapy accounted for $35.6 \%$. Analysis using the SPSS software revealed a $\kappa$ value equal to 0.507 , indicating that the data extracted by the two investigators were consistent.

TABLE 1 | Features of the included studies.

\begin{tabular}{|c|c|c|c|c|c|c|}
\hline References & Countr & y Tumor type & Therapy /Control & No. of patients & $\begin{array}{l}\text { Study } \\
\text { design }\end{array}$ & Clinical factors \\
\hline Edeline et al. (8) & France & $\begin{array}{l}\text { Bile duct cancer and gallbladder } \\
\text { cancer }\end{array}$ & GEM vs. OB & $73 / 82$ & $\mathrm{RCT}$ & 1-year OS median-RFS N(+)-OS R(+)-OS \\
\hline Primrose et al. (10) & UK & $\begin{array}{l}\text { Bile duct cancer and gallbladder } \\
\text { cancer }\end{array}$ & FU vs. OB & $223 / 224$ & RCT & 5-year OS median-RFS N(+)-OS R(+)-OS \\
\hline \multirow[t]{3}{*}{ Ebata et al. (9) } & \multirow[t]{3}{*}{ Japan } & \multirow[t]{3}{*}{ Bile duct cancer } & \multirow[t]{3}{*}{ GEM vs. OB } & \multirow[t]{3}{*}{$117 / 108$} & \multirow[t]{3}{*}{ RCT } & 5-year OS median-RFS \\
\hline & & & & & & $\mathrm{N}(+)-\mathrm{OS}$ \\
\hline & & & & & & $\mathrm{R}(+)-\mathrm{OS}$ \\
\hline Leng et al. (28) & USA & Bile duct cancer & RT vs. OB & $762 / 1155$ & Retro- & 5-year OS \\
\hline Mizuno et al. (29) & Japan & Bile duct cancer & GEM vs. OB & $67 / 113$ & Retro- & 5-year OS median-RFS \\
\hline Go et al. (31) & Korea & Gallbladder cancer & CRT vs. FU & $45 / 39$ & Retro- & 5-year OS median-RFS N(+)-OS \\
\hline Im et al. (32) & Korea & Bile duct cancer & CRT vs. OB vs. RT & $49 / 168 / 29$ & Retro- & 5-year OS median-RFS R(+)-OS \\
\hline Dover et al. (30) & USA & Bile duct cancer & CRT vs. OB & $23 / 72$ & Retro- & $\mathrm{R}(+)-\mathrm{OS}$ \\
\hline Wang et al. (33) & USA & Gallbladder cacner & CRT vs. OB & $68 / 44$ & Retro- & 5-year OS median-RFS \\
\hline Toyoki et al. (34) & Japan & Bile duct cancer & FU vs. OB & $55 / 99$ & Retro- & 5-year OS \\
\hline Hoehn et al. (35) & USA & Bile duct cancer & CRT vs. OB & $1902 / 5739$ & Retro- & $\mathrm{N}(+)$-OS R(+)-OS \\
\hline Hyder et al. (36) & USA & Gallbladder cancer & RT vs. OB & $894 / 894$ & Retro- & 1-year OS 5-year OS \\
\hline Neoptolemos et al. (26) & UK & Bile duct cancer & GEM vs. OB vs. FU & $146 / 145 / 143$ & RCT & 1-year OS 5-year OS \\
\hline Narang et al. (37) & USA & Bile duct cancer & CRT vs. OB & $66 / 120$ & Retro- & 5-year OS median-RFS \\
\hline Kim et al. (38) & Korea & Bile duct cancer & CRT vs. OB & $115 / 53$ & Retro- & 5-year OS median-RFS \\
\hline Murakami et al. (39) & Japan & Bile duct cancer & GEM vs. OB & $49 / 78$ & Retro- & 1-year OS 5-year OS \\
\hline Gold et al. (40) & USA & Gallbladder cancer & CRT vs. OB & $25 / 48$ & Retro- & 1-year OS 5-year OS median-RFS \\
\hline Murakami et al. (41) & Japan & $\begin{array}{l}\text { Bile duct cancer and gallbladder } \\
\text { cancer }\end{array}$ & GEM vs. OB & $50 / 53$ & Retro- & 1-year OS 5-year OS \\
\hline Borghero et al. (42) & USA & Bile duct cancer & CRT vs. OB & $42 / 23$ & Retro- & 5-year OS median-RFS \\
\hline Hughe et al. (43) & USA & Bile duct cancer & CRT vs. OB & $34 / 30$ & Retro- & 1-year OS 5-year OS \\
\hline Sikora et al. (44) & India & Bile duct cancer & CRT vs. OB & $49 / 55$ & Retro- & 1-year OS 5-year OS \\
\hline Takada et al. (27) & Japan & Gallbladder cancer & 5-FU vs. OB & $69 / 43$ & $\mathrm{RCT}$ & 1-year OS 5-year OS median-RFS \\
\hline & & Bile duct cancer & 5-FU vs. OB & $82 / 84$ & $\mathrm{RCT}$ & 1-year OS 5-year OS median-RFS \\
\hline
\end{tabular}



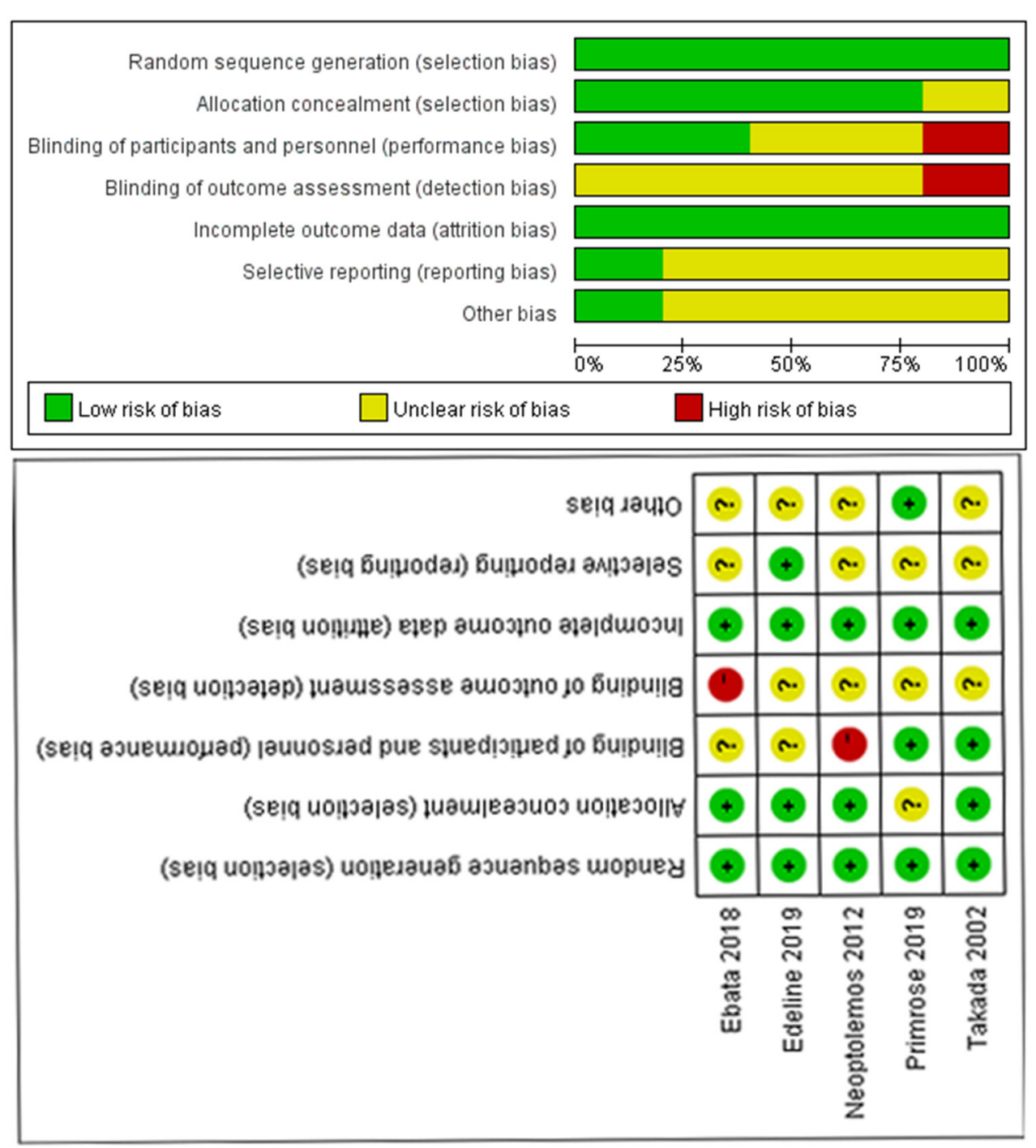

FIGURE 3 | Quality assessment chart.

In the current study, five interventions were categorized into seven different comparison groups, namely the GEM vs. OB, 5 -FU vs. OB, RT vs. OB, CRT vs. FU, CRT vs. OB, CRT vs. RT, and GEM vs. 5-FU groups. All patients were treated with one of the five aforementioned therapies (Figure 2). Of the 22 studies we included, the dose of chemotherapy was not completely consistent according to the patient's condition in different studies. Thirteen studies involved radiotherapy, and 9 studies specified the radiotherapy dose (median radiation dose was $50.4 \mathrm{~Gy}$ ), only 2 studies specified radiotherapy type. In the 22 eligible studies, five RCTs $(8-10,26,27)$ and 17 retrospective studies (28-44) were included. In addition, these studies were conducted in different countries, and more specifically, nine in the US $(30,33,35-37,40,42,43)$, six in Japan $(9,15$, 27, 29, 33-35, 39-41, 45, 46), three in Korea (31, 32, 38), two in UK $(10,26)$, one in France (8) and one in India (44). The sample size in each study ranged from 25 to 5,739 patients. A total of 9,430 patients underwent BTC resection alone, while 5,216 patients were treated with surgery and adjuvant therapy. In terms of tumor sites, four studies involved two sites, including the bile duct and the gallbladder, 14 studies only the bile duct, and the remaining four the gallbladder. Finally, among the 22 studies, two were three-arm trials and the remaining 20 two-arm trials. All data are summarized in Table 1.

\section{Quality Assessment}

Following the selection of eligible studies, the quality of the included studies was subsequently evaluated. Therefore, the Cochrane Collaboration's tool, covering five domains of bias, 
TABLE 2 | Quality assessment of retrospective studies.

\begin{tabular}{|c|c|c|c|c|c|c|c|c|c|}
\hline References & $\begin{array}{l}\text { Is the case } \\
\text { definition } \\
\text { adequate? }\end{array}$ & $\begin{array}{l}\text { Representativeness } \\
\text { of cases }\end{array}$ & $\begin{array}{l}\text { Selection of } \\
\text { Controls }\end{array}$ & $\begin{array}{l}\text { Definition of } \\
\text { Controls }\end{array}$ & $\begin{array}{l}\text { Comparability of } \\
\text { cases and controls } \\
\text { on the basis of the } \\
\text { design or analysis }\end{array}$ & $\begin{array}{l}\text { Ascertainment } \\
\text { of exposure }\end{array}$ & $\begin{array}{l}\text { Same method of } \\
\text { Ascertainment for } \\
\text { cases and controls }\end{array}$ & $\begin{array}{c}\text { Non- } \\
\text { Response }\end{array}$ & Total score \\
\hline Leng et al. (28) & 1 & 1 & 1 & 0 & 1 & 1 & 1 & 1 & 7 \\
\hline Mizuno et al. (29) & 1 & 1 & 1 & 0 & 2 & 1 & 1 & 1 & 8 \\
\hline Go et al. (31) & 1 & 1 & 1 & 1 & 1 & 1 & 1 & 0 & 7 \\
\hline Im et al. (32) & 1 & 1 & 1 & 1 & 1 & 1 & 1 & 1 & 8 \\
\hline Dover et al. (30) & 1 & 1 & 1 & 0 & 1 & 1 & 1 & 1 & 7 \\
\hline Wang et al. (33) & 1 & 1 & 1 & 0 & 1 & 1 & 1 & 1 & 7 \\
\hline Toyoki et al. (34) & 1 & 1 & 1 & 0 & 1 & 1 & 1 & 1 & 7 \\
\hline Hoehn et al. (35) & 1 & 1 & 1 & 0 & 1 & 1 & 1 & 1 & 7 \\
\hline Hyder et al. (36) & 1 & 1 & 1 & 1 & 1 & 1 & 1 & 0 & 7 \\
\hline Narang et al. (37) & 1 & 0 & 1 & 1 & 1 & 1 & 1 & 0 & 6 \\
\hline Kim et al. (38) & 1 & 1 & 1 & 0 & 1 & 1 & 1 & 0 & 6 \\
\hline Murakami et al. (39) & 1 & 1 & 1 & 0 & 1 & 1 & 1 & 1 & 7 \\
\hline Gold et al. (40) & 1 & 1 & 1 & 0 & 1 & 1 & 1 & 0 & 6 \\
\hline Murakami et al. (41) & 1 & 1 & 1 & 0 & 1 & 1 & 1 & 0 & 6 \\
\hline Borghero et al. (42) & 1 & 1 & 1 & 1 & 1 & 1 & 1 & 1 & 8 \\
\hline Hughe et al. (43) & 1 & 1 & 1 & 0 & 1 & 1 & 1 & 1 & 7 \\
\hline Sikora et al. (44) & 1 & 1 & 1 & 1 & 1 & 1 & 1 & 1 & 8 \\
\hline
\end{tabular}


namely the selection bias, performance bias, attrition bias, measurement bias, and reporting bias, was applied to evaluate RCT risk of bias and quality of evidence. In Figure 3, green, yellow, and red represents low, unclear, and high risk of bias, respectively. The analysis revealed that all five RCTs exhibited high quality and low risk of bias (Figure 3). Furthermore, NOS was employed to assess the quality of retrospective studies. In NOS, three domains of evaluation of the risk of bias are included, namely the research subject selection, intergroup comparability, and measurement of exposure factors. A maximum of nine points are available, and a total score $\geq 6$ is considered to indicate high quality. Herein, NOS results demonstrated that all studies displayed a score of $\geq 6$ (Table 1), thus suggesting that the quality of all retrospective studies was high. The quality rate of RCTs is summarized in Table 2.

\section{Evaluation of Heterogeneity}

Subsequently, the heterogeneity among the selected studies was evaluated based on three outcome indicators, namely the 1-year

TABLE 3 | Heterogeneity assessment among studies in terms of different outcomes.

\begin{tabular}{lccc}
\hline Category & 1-year OS $\left(^{\mathbf{2}}\right)$ & 5-year OS $\left(\boldsymbol{I}^{\mathbf{2}}\right)$ & Median-RFS $\left(\boldsymbol{I}^{\mathbf{2}}\right)$ \\
\hline GEM vs. OB & $36.10 \%$ & $76.70 \%$ & $84.70 \%$ \\
CRT vs. OB & $0.00 \%$ & $0.00 \%$ & $53.80 \%$ \\
RT vs. OB & $0.00 \%$ & $69.10 \%$ & $0.00 \%$ \\
FU vs. OB & $0.00 \%$ & $35.20 \%$ & $0.00 \%$
\end{tabular}

OS rate, 5-year OS rate, and median-RFS rate (Table 2). For 1year OS rate, the $\mathrm{I}^{2}$ value for each comparison group, namely the 5 -FU vs. $\mathrm{OB}\left(\mathrm{I}^{2}=0 \%\right)$, RT vs. OB $\left(\mathrm{I}^{2}=0 \%\right)$, CRT vs. OB $\left(\mathrm{I}^{2}=0 \%\right)$, and GEM vs. OB $\left(\mathrm{I}^{2}=36.1 \%\right)$ group, was $<50 \%$. Additionally, for 5-year OS rate, the $\mathrm{I}^{2}$ values for the 5 -FU vs. $\mathrm{OB}$, and CRT vs. OB comparison groups were 35.2 and $0 \%$, respectively. For median-RFS rate, the $\mathrm{I}^{2}$ value of the $5-\mathrm{FU}$ vs. $\mathrm{OB}$, and RT vs. OB comparison groups was $0 \%$ for both groups. The aforementioned results indicated a low heterogeneity among groups. By contrast, in the RT vs. OB comparison group, the $\mathrm{I}^{2}$ value was $69.1 \%$ for the 5-year OS rate, supporting a high heterogeneity (Table 3). Subsequently, a subgroup analysis, based on tumor site, revealed that heterogeneity was reduced to $0 \%$, suggesting that tumor site was one of the major factors affecting heterogeneity. When the studies were divided into RCTs and non-RCTs, the $\mathrm{I}^{2}$ value of the GEM vs. OB comparison group was decreased from 76.7 to $50 \%$ in terms of 5 -year OS rate, and from 84.7 to $0 \%$ in terms of median-RFS rate. These findings confirmed the effect of research design on heterogeneity. In addition, when study location was used as a variable for subgroup analysis, the $\mathrm{I}^{2}$ value of the CRT vs. OB comparison group was decreased from 53.8 to $41.2 \%$ in terms of median-RFS rate, suggesting that geographical distribution could also contribute to heterogeneity among studies.

\section{Consistency Assessment and Network Analysis}

Both direct and indirect comparisons in the GEM vs. 5-FU group were then carried out, and the results showed that Bayesian $P$ value was $>0.05$ in terms of 1 -year OS rate (Figure $4 \mathrm{~A}$ ). Additionally, in different comparison groups, the $P$ values of
A

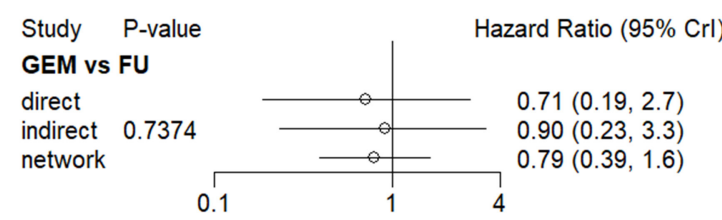

C

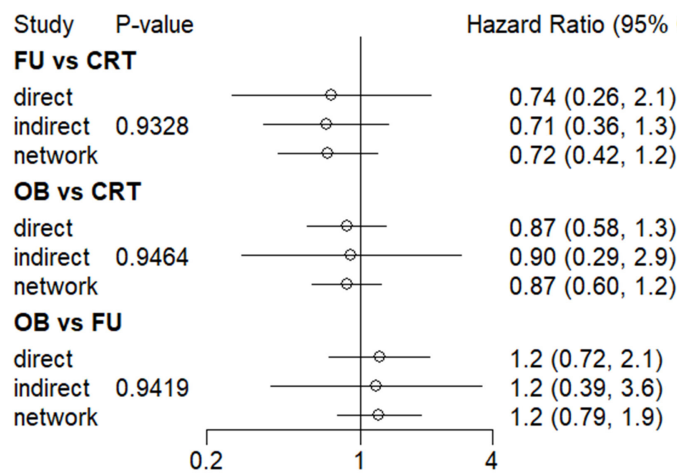

B

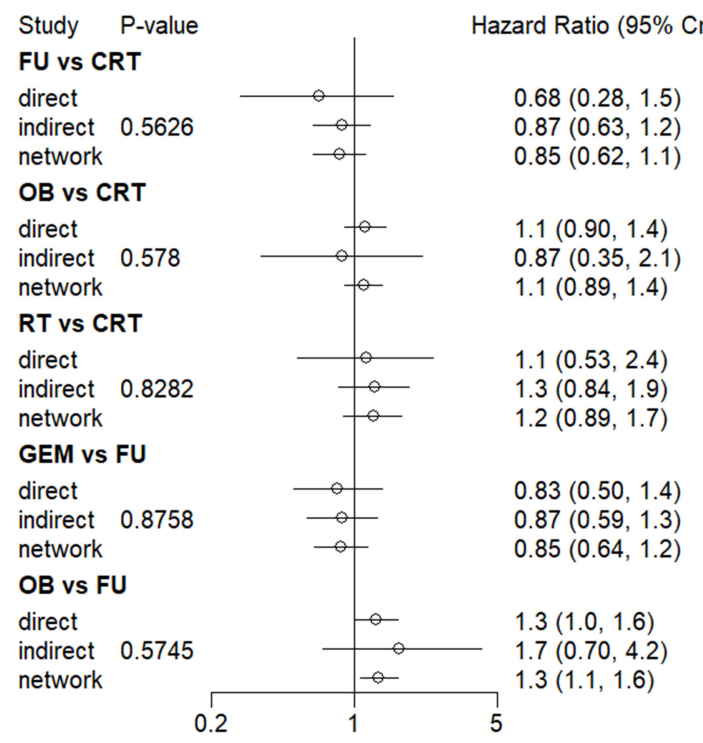

FIGURE 4 | Consistency evaluation using forest plots. The (A) 1-year OS, (B) 5-year OS, and (C) median-RFS rates are presented. OS, overall survival; RFS, recurrence-free survival. 


\begin{tabular}{lllll} 
A & & & & \\
\hline CRT & $1.66(0.56,5.36)$ & $1.24(0.41,4.05)$ & $1.50(0.63,4.00)$ & $0.96(0.25,4.12)$ \\
\hline $0.60(0.19,1.79)$ & FU & $0.74(0.32,1.79)$ & $0.91(0.46,1.86)$ & $0.59(0.16,2.11)$ \\
$0.80(0.25,2.43)$ & $1.35(0.56,3.12)$ & GEM & $1.21(0.62,2.37)$ & $0.79(0.22,2.86)$ \\
$0.67(0.25,1.59)$ & $1.10(0.54,2.17)$ & $0.82(0.42,1.63)$ & OB & $0.65(0.22,1.88)$ \\
\hline $1.04(0.24,3.98)$ & $1.69(0.47,6.17)$ & $1.27(0.35,4.61)$ & $1.54(0.53,4.57)$ & RT \\
\hline B & & & & \\
\hline CRT & $0.75(0.46,1.20)$ & $0.59(0.34,0.97)$ & $1.19(0.84,1.67)$ & $1.46(0.84,2.43)$ \\
\hline $1.33(0.83,2.16)$ & FU & $0.78(0.46,1.28)$ & $1.58(1.09,2.31)$ & $1.94(1.10,3.45)$ \\
$1.71(1.03,2.95)$ & $1.29(0.78,2.17)$ & GEM & $2.02(1.36,3.07)$ & $2.48(1.41,4.55)$ \\
$0.84(0.60,1.19)$ & $0.63(0.43,0.92)$ & $0.49(0.33,0.73)$ & OB & $1.23(0.79,1.88)$ \\
\hline $0.69(0.41,1.19)$ & $0.52(0.29,0.91)$ & $0.40(0.22,0.71)$ & $0.81(0.53,1.27)$ & RT \\
\hline C & & & & \\
\hline CRT & $0.61(0.26,1.35)$ & $0.50(0.19,1.32)$ & $0.85(0.49,1.47)$ & $0.59(0.15,2.38)$ \\
\hline $1.65(0.74,3.89)$ & FU & $0.82(0.29,2.48)$ & $1.42(0.69,2.99)$ & $0.98(0.21,4.58)$ \\
$2.01(0.76,5.20)$ & $1.21(0.40,3.41)$ & GEM & $1.70(0.78,3.75)$ & $1.19(0.24,5.67)$ \\
$1.17(0.68,2.03)$ & $0.70(0.33,1.44)$ & $0.59(0.27,1.28)$ & OB & $0.70(0.17,2.69)$ \\
$1.68(0.42,6.89)$ & $1.02(0.22,4.71)$ & $0.84(0.18,4.13)$ & $1.43(0.37,5.80)$ & RT \\
\hline
\end{tabular}

FIGURE 5 | Comparison of efficacy among five adjuvant therapies. The pooled hazard ratios for the (A) 1-year OS, (B) 5-year OS, and (C) median-RFS rates are presented. The data in the upper right part represent the results obtained when the treatment on the row was compared with that in the column, while the data in the lower-left part represent the results obtained when the treatment on the column was compared with that on the row. OS, overall survival; RFS, recurrence-free survival.

direct and indirect comparisons were also $>0.05$ in terms of the 5 -year OS rate and median-RFS rate (Figures 4B,C). Therefore, no significant inconsistencies were observed between direct and indirect comparisons.

The network analysis results are presented in Figure 5. For 1-year OS rate, no statistically significant differences were observed between adjuvant therapy and OB (Figure 5A). More importantly, the analysis revealed that treatment with RT as adjuvant therapy could prolong the 1-year OS rate, compared with GEM $(\mathrm{HR}=0.79), 5-\mathrm{FU}(\mathrm{HR}=0.59)$, OB $(\mathrm{HR}=0.65)$, and CRT (HR =0.96). However, when the efficacy of different adjuvant therapies was ranked without considering toxicity, the effectiveness of CRT (51\%) was higher compared with RT (40\%), in terms of 1-year OS rate (Figure 6A). Additionally, GEM exhibited a significantly higher 5-year OS rate compared with CRT $(\mathrm{HR}=0.59 ; 95 \% \mathrm{CI}=0.34-0.97)$, OB $(\mathrm{HR}=0.49$; $95 \% \mathrm{CI}=0.33-0.73)$, and RT $(\mathrm{HR}=0.40 ; 95 \% \mathrm{CI}=0.22-$ 0.71 ; Figure 5B). In terms of 5-year OS rate, 5-FU displayed better efficacy compared with $\mathrm{OB}(\mathrm{HR}=0.63 ; 95 \% \mathrm{CI}=$ $0.43-0.92)$ and $\mathrm{RT}(\mathrm{HR}=0.52 ; 95 \% \mathrm{CI}=0.29-0.91)$, and worse compared with GEM $(\mathrm{HR}=1.29 ; 95 \% \mathrm{CI}=0.78-2.17)$. No statistically significant differences were observed among the remaining comparison groups. As shown in Figure 6B, GEM was more likely to rank first for 5 -year OS rate $(83 \%)$. Furthermore, a detailed analysis was performed to determine whether adjuvant therapy could provide benefits in median-RFS rate. Therefore, compared with other adjuvant therapies, GEM displayed a greater tendency to provide median-RFS benefits (Figures 5C, 6C).

Given that tumors of the gallbladder and bile duct are etiologically different, it is more likely to respond differently to treatment. Therefore, the tumor sites were divided into different subgroups for analysis. The results revealed that for patients with cholangiocarcinoma, GEM ranked first (63\%) among these interventions, and was the only effective therapy that could prolong the 5-year OS rate compared with $\mathrm{OB}(\mathrm{HR}=0.55$; $95 \% \mathrm{CI}=0.34-0.91)$. There were no statistically significant differences among the remaining comparison groups. Regarding gallbladder cancer, CRT (74\%) and 5-FU (85\%) therapies were more likely to prolong 1 -year and 5-year OS, respectively. However, the comparison between these results did not reach statistical significance. $\mathrm{R}^{+}$and $\mathrm{N}^{+}$are considered the most important risk factors for tumor recurrence, therefore, adjuvant therapy is particularly pivotal. The results of the comprehensive analysis showed that postoperative CRT could significantly improve the OS rate of $\mathrm{N}^{+}$(Figure 7A) and $\mathrm{R}^{+}$(Figure 7B) patients $(\mathrm{HR}=0.69 ; 95 \% \mathrm{CI}=0.49-1.00$; and $\mathrm{HR}=0.22$; $95 \% \mathrm{CI}=0.074-0.66)$.

\section{Publication Bias}

The meta-funnel method was used to evaluate publication bias. The asymmetry of funnel plots for 1-year OS rate (Figure 8A), 5year OS rate (Figure 8B), and median- RFS (Figure 8C) reflected the evidence of publication bias. The different colors in the funnel plots represent different comparison pairs. The dots beyond the slashes on both sides represent studies with a small sample size, which may exaggerate the effect of interventions. The results did not reveal any evidence of publication bias in the current study.

\section{Quality of the Evidence}

In the present study, the quality of the selected five RCTs was moderate, and all risks of bias were considered low to moderate. The quality score of the 17 retrospective studies was $\geq 6$, indicating good quality. However, the small number of 


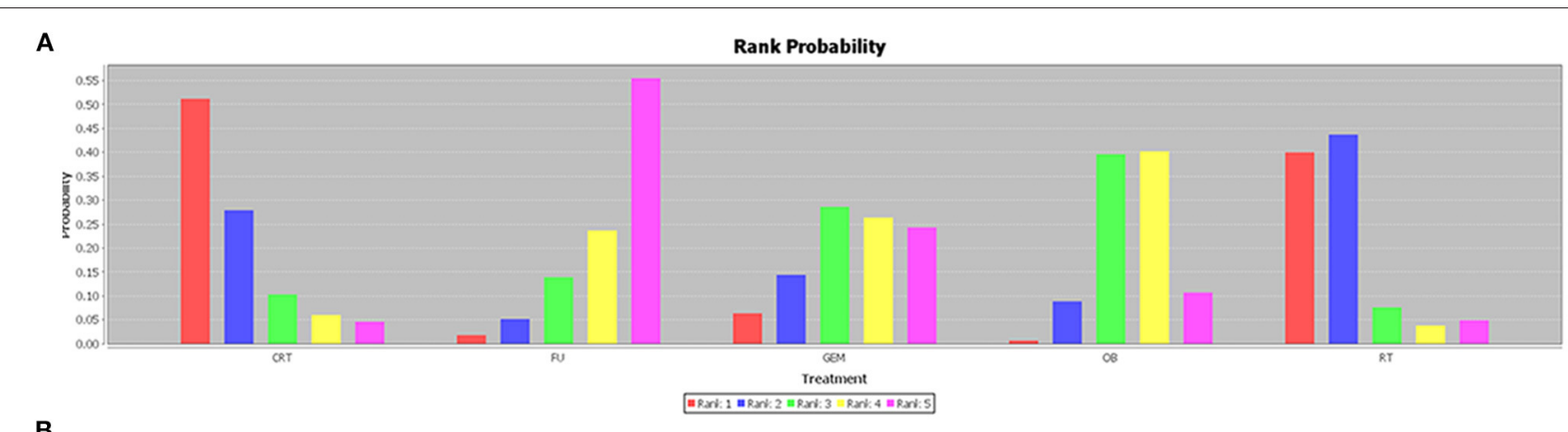

B

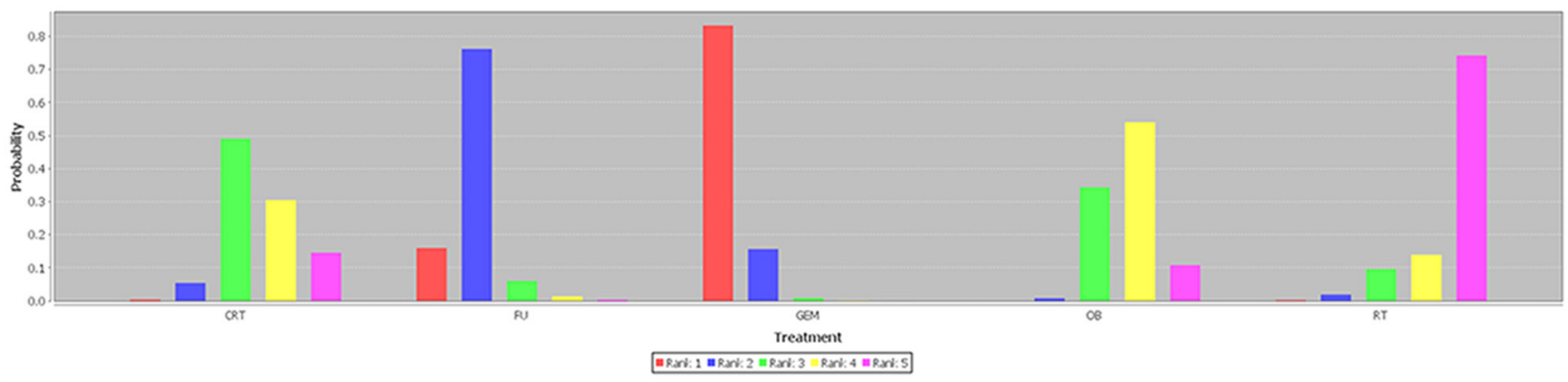

C

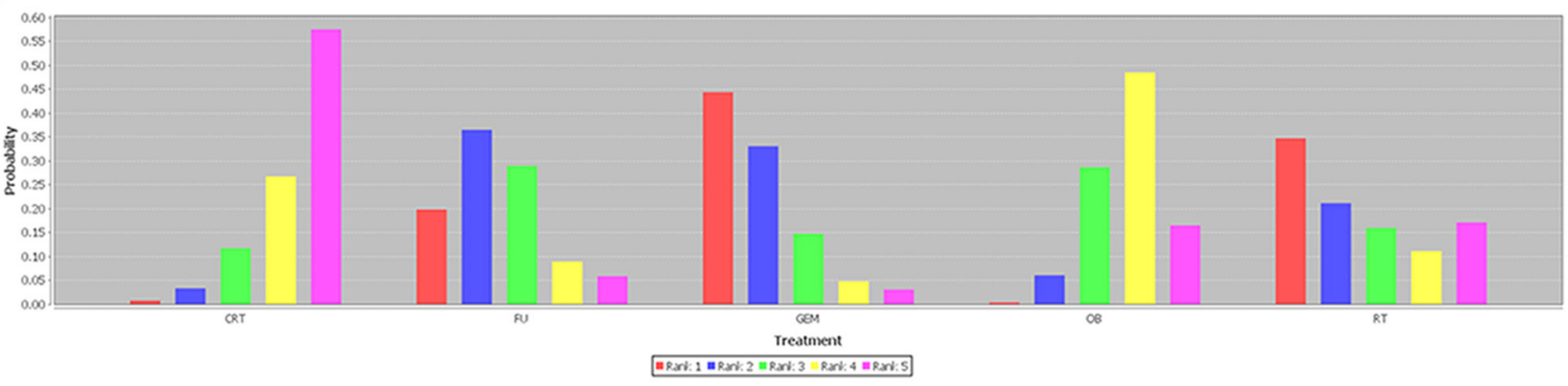

FIGURE 6 | Efficacy rank histogram of different outcomes. The (A) 1-year OS, (B) 5-year OS, and (C) median-RFS rates are presented. Different colors correspond to different efficacy ranking. The higher the red column, the more likely to rank first. OS, overall survival; RFS, recurrence-free survival.

head-to-head comparisons contributed to a serious inaccuracy, which affected the strength of inferences within the Bayesian network. In terms of heterogeneity, the GEM vs. OB comparison group presented higher heterogeneity for different outcomes, which also affected the evidence strength. Therefore, a subgroup analysis was carried out to reveal the sources of heterogeneity. Little evidence of inconsistency was observed between the direct and indirect assessments for the majority of comparisons $(P>$ 0.05). It is well known that small sample-sized studies may affect the publication bias. However, in the present study only three small sample-sized trials, beyond the slashes on both sides of the funnel plots, contributed to publication bias. Overall, the strength of evidence was considered moderate to high, supporting the efficacy of GEM and 5-FU in extending 5-year OS compared with OB.

\section{DISCUSSION}

Currently, the research on adjuvant therapy for BTC is a hot issue, therefore, the association between adjuvant therapy and clinical outcome has been widely investigated. Since the existing trials are often small-sized and their findings are controversial, it remains difficult to determine whether resected BTC patients should undergo adjuvant therapy, and which type of therapy is more effective. Herein, a total of 22 studies, including 5 RCTs and 17 non-RCTs, were included in the Bayesian network analysis. The first-ranking adjuvant therapy was selected among seven comparison groups, namely the GEM vs. OB, 5-FU vs. OB, RT vs. OB, CRT vs. 5-FU, CRT vs. OB, CRT vs. RT, and GEM vs. 5-FU groups. The results of the current study provided strong evidence that both GEM and 5-FU, as adjuvant therapies, could provide BTC patients with long-term survival benefits, while GEM tended to exhibit a better efficacy compared with 5 -FU ( HR $=0.78 ; 95 \%$ $\mathrm{CI}=0.46-1.28)$. In addition, for patients with $\mathrm{N}^{+}$and $\mathrm{R}^{+}, \mathrm{CRT}$ could increase the OS rate compared with OB (HR $=0.69 ; 95 \%$ $\mathrm{CI}=0.49-1$; and $\mathrm{HR}=0.22 ; 95 \% \mathrm{CI}=0.074-0.66)$, whereas $\mathrm{RT}$ could not provide any survival advantage.

CRT regimen for $\mathrm{R}^{+}$patients has been widely adapted in clinical practice. However, for $\mathrm{N}^{+}$patients, the available findings regarding the choice of chemotherapy or chemoradiotherapy 


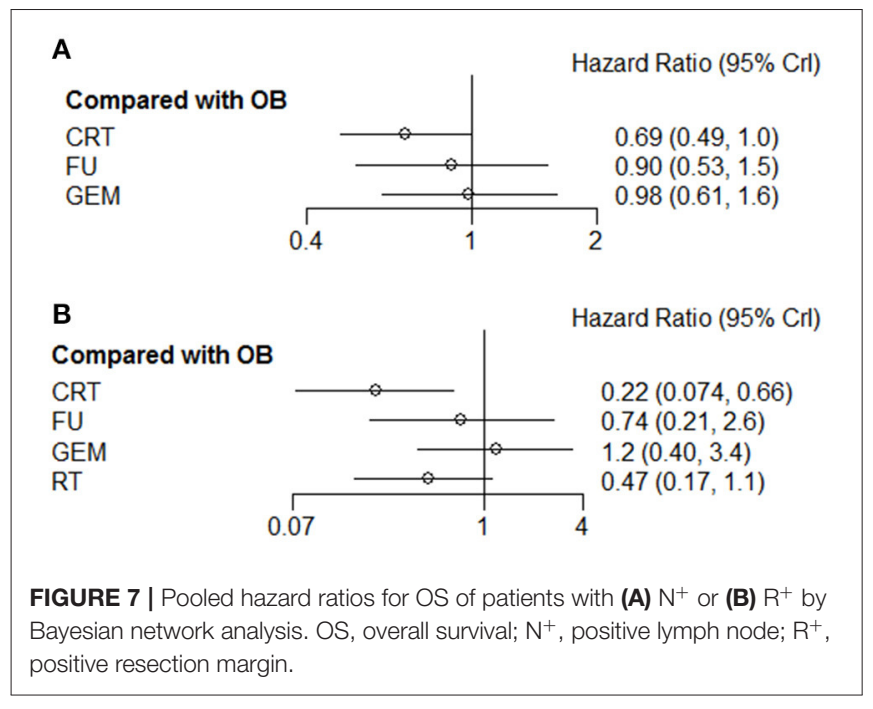

remain controversial. Numerous studies have reported that $\mathrm{R}^{+}$ and $\mathrm{N}^{+}$are negative predictors of survival for BTC patients (45-48). Based on these findings, Horgan et al. (6) conducted a meta-analysis to determine the effect of adjuvant therapy on survival rate. Consistent with the findings of the current study, the subgroup analysis in the above study showed that treatment with CRT (OR $=0.39 ; 95 \% \mathrm{CI}=0.61-0.98)$ adjuvant therapy could provide survival advantage in $\mathrm{N}^{+}(\mathrm{OR}=0.49 ; P=004)$ and $\mathrm{R}^{+}(\mathrm{OR}=0.36 ; P=002)$ patients, thus supporting the effective role of CRT as adjuvant therapy. However, the meta-analysis by Horgan et al. (6) classified all different treatments into the same class and no indirect comparison between treatments. Another analysis concluded that adjuvant chemotherapy administration gave an OS benefit in resected BTC, but this study didn't include treatment measures other than chemotherapy (49). Herein, all primary therapies (GEM, 5-FU, CRT, RT, and OB) were simultaneously compared, and the effect of each therapy was evaluated individually. Inconsistent with our results, another study showed that treatment with CRT did not provide longterm survival benefits for $\mathrm{N}^{+}(\mathrm{HR}=2.10$; 95\% CI $=0.31$ 14.34) and $\mathrm{R}^{+}$patients $(\mathrm{HR}=0.58 ; 95 \% \mathrm{CI}=0.06-6.17)(7)$. Such inconsistency could be attributed to more credible and robust data included in the current study. Therefore, our results could offer clinicians the necessary knowledge for selecting the appropriate adjuvant therapy for $\mathrm{N}^{+}$and $\mathrm{R}^{+}$patients.

The Bayesian analysis demonstrated that GEM and 5-FU could decrease mortality in patients with resected-BTC. This finding was partially consistent with a previous study conducted by Zhu GQ et al., indicating that intravenous GEM was closely associated with prolonged survival. The above network metaanalysis aimed to investigate the association between adjuvant therapy and survival, demonstrating that that GEM after surgery had manageable toxicity, and could significantly prolong survival of BTC patients $(\mathrm{HR}=2.12 ; 95 \% \mathrm{CI}=1.23-4.02 ; P=0.01)$ (7). Furthermore, the BILCAP trial was the only RCT to reveal a significant difference on $\mathrm{OS}$ in the 5 -FU vs. OB comparison group $(\mathrm{HR}=0.75 ; 95 \% \mathrm{CI}=0.58-0.97 ; P=0.028)$, using a

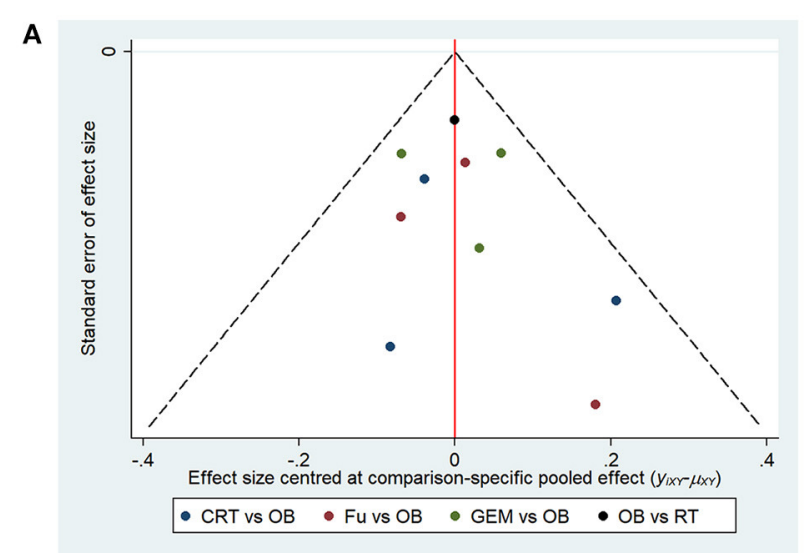

B

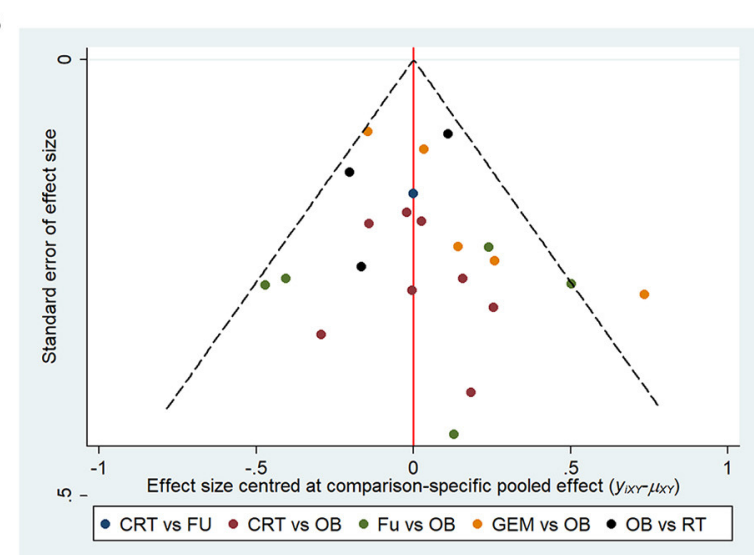

C

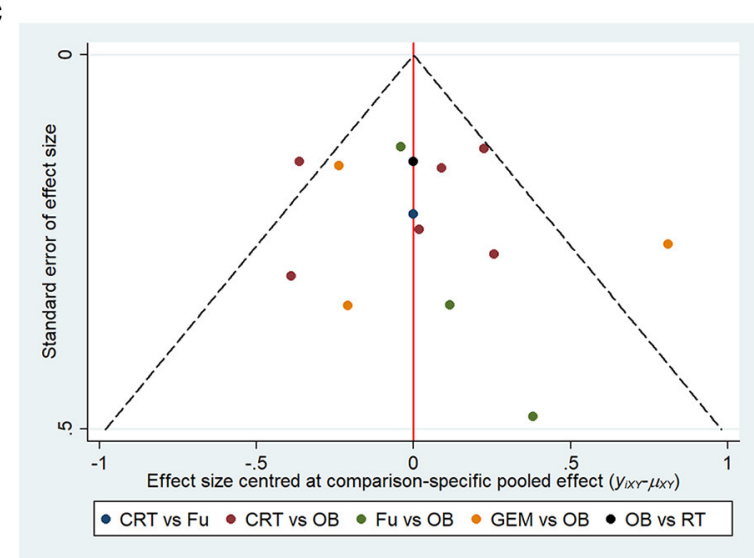

FIGURE 8 | Funnel plots represent publication bias in terms of (A) 1-year OS, (B) 5-year OS, and (C) median-RFS rate. Different color dots represent different comparisons. The red line in the middle represents the null hypothesis, where the specific effect values in the trial are similar to that of the pooled effect sizes in comparisons.

per-protocol analysis. However, in terms of unadjusted intentionto-treat (ITT) OS, no statistically significant differences were observed $(\mathrm{HR}=0.81 ; 95 \% \mathrm{CI}=0.63-1.04 ; P=0.097)$. Due to the inconsistency between ITT and per-protocol analysis, the quality 
of evidence was considered moderate to strong. In addition, the RCT by Ebata et al. (9) and the PRODIGE12 study reported similar results. Therefore, there was no significant difference in survival probability between the GEM and OB group in patients with resected-BTC $(8,9)$. This finding could be attributed to small sample size and decreased event rate. The present study was the first to assess the survival benefits, by performing direct and indirect comparisons among five different adjuvant therapies. Additionally, the results supported the conclusion that both GEM and 5-FU could provide survival advantages compared with $\mathrm{OB}$, while GEM was more effective than 5-FU $(\mathrm{HR}=0.78)$. However, head-to-head studies are still lacking. In Europe, the first head-to-head trial has currently begun, employing GEM in the experimental group, and patients switching from $\mathrm{OB}$ to 5$\mathrm{FU}$ in the control group. The aforementioned trial could provide substantial evidence supporting the treatment of resected BTC patients with GEM or 5-FU (50). Herein, the Bayesian analysis with the strongest clinical evidence also provided a reference for the selection of appropriate treatment strategies.

The current study summarized all the reliable large samplesized retrospective studies and RCTs in recent years, regarding the effect of different types of adjuvant therapy on BTC patients, by acquiring more comprehensive data compared with previous studies. The results could provide clinicians with the necessary knowledge for selecting the appropriate adjuvant therapy for BTC patients. The Bayesian network analysis also helped to avoid unnecessary selection bias by incorporating all present data into a single analysis (51). When no head-to-head trials are available, network meta-analysis is of great importance, since all indirect and direct comparison results can be combined in order to achieve a more accurate evaluation of the result (52). However, there are still some limitations in this study. For example, only five RCTs were included in the analysis, while the rest were retrospective studies. Secondly, no gray literature sources were searched. In addition, toxicity analysis was not carried out since most selected studies lacked data on adverse reactions. When data on adverse reactions were reported, these could not be included in the analysis due to high heterogeneity. Fourthly, data on lymph nodes and margins are still scarce in the published literature. In addition, data on surgical methods, different radiation and chemotherapy doses are

\section{REFERENCES}

1. Akinyemiju T, Abera S, Ahmed M, Alam N, Alemayohu MA, Allen $\mathrm{C}$, et al. The burden of primary liver cancer and underlying etiologies from 1990 to 2015 at the Global, Regional, and National Level: results From the Global Burden of Disease Study 2015. JAMA Oncol. (2017) 3:1683-91. doi: 10.1001/jamaoncol.2017.3055

2. Blechacz B, Komuta M, Roskams T, Gores GJ. Clinical diagnosis and staging of cholangiocarcinoma. Nat Rev Gastroenterol Hepatol. (2011) 8:51222. doi: $10.1038 /$ nrgastro.2011.131

3. Bridgewater J, Galle PR, Khan SA, Llovet JM, Park JW, Patel T, et al. Guidelines for the diagnosis and management of intrahepatic cholangiocarcinoma. $J$ Hepatol. (2014) 60:1268-89. doi: 10.1016/j.jhep.2014.01.021

4. Razumilava N, Gores GJ. Cholangiocarcinoma. Lancet. (2014) 383:216879. doi: 10.1016/S0140-6736(13)61903-0 insufficient, hierarchical analysis cannot be conducted. Finally, assessments on lymph node and margin status varied due to operation quality.

\section{CONCLUSION}

In summary, this network analysis indicated that compared with surgery alone, adjuvant therapy included GEM- and 5-FU-based chemotherapy schemes could prolonged OS in BTC patients. Furthermore, GEM was more effective than 5-FU, and provided benefits on RFS rate. For $\mathrm{N}^{+}$and $\mathrm{R}^{+}$patients, CRT performance was associated with prolonged OS. In addition, the difference between adjuvant therapy and $\mathrm{OB}$ was not statistically significant in terms of short-term survival time, however, treatment with CRT or RT could improve survival of BTC patients.

\section{DATA AVAILABILITY STATEMENT}

The original contributions presented in the study are included in the article/supplementary files, further inquiries can be directed to the corresponding author/s.

\section{AUTHOR CONTRIBUTIONS}

$\mathrm{XC}$ and FM designed the research study, performed the analyses, and wrote the manuscript. YZ and HX critically revised the manuscript, performed and ensured correct analysis of the data. All authors contributed to the article and approved the submitted version.

\section{FUNDING}

This work was supported by the Natural Science Foundation of Hubei Province (grant no. 2018CFB611).

\section{ACKNOWLEDGMENTS}

We would like to acknowledge YZ and all the team of the Department of Oncology, Tongji Hospital, Tongji Medical College, Huazhong University of Science and Technology for their support in completing the current study.

5. Valle JW, Borbath I, Khan SA, Huguet F, Gruenberger T, Arnold D, et al. Biliary cancer: ESMO Clinical Practice Guidelines for diagnosis, treatment and follow-up. Ann Oncol. (2016) 27(suppl 5):v28-v37. doi: 10.1093/annonc/mdw324

6. Horgan AM, Amir E, Walter T, Knox JJ. Adjuvant therapy in the treatment of biliary tract cancer: a systematic review and meta-analysis. J Clin Oncol. (2012) 30:1934-40. doi: 10.1200/JCO.2011.40.5381

7. Zhu GQ, Shi KQ, You J, Zou H, Lin YQ, Wang LR, et al. Systematic review with network meta-analysis: adjuvant therapy for resected biliary tract cancer. Aliment Pharmacol Ther. (2014) 40:759-70. doi: 10.1111/apt.12900

8. Edeline J, Benabdelghani M, Bertaut A, Watelet J, Hammel P, Joly JP, et al. Gemcitabine and Oxaliplatin Chemotherapy or Surveillance in Resected Biliary Tract Cancer (PRODIGE 12-ACCORD 18-UNICANCER GI): A Randomized Phase III Study. J Clin Oncol. (2019) 37:65867. doi: 10.1200/JCO.18.00050 
9. Ebata T, Hirano S, Konishi M, Uesaka K, Tsuchiya Y, Ohtsuka M, et al. Randomized clinical trial of adjuvant gemcitabine chemotherapy versus observation in resected bile duct cancer. Br J Surg. (2018) 105:192202. doi: 10.1016/j.hpb.2018.06.002

10. Primrose JN, Fox RP, Palmer DH, Malik HZ, Prasad R, Mirza D, et al. Capecitabine compared with observation in resected biliary tract cancer (BILCAP): a randomised, controlled, multicentre, phase 3 study. Lancet Oncol. (2019) 20:663-73. doi: 10.1016/S1470-2045(18)30915-X

11. Hutton B, Salanti G, Caldwell DM, Chaimani A, Schmid CH, Cameron C, et al. The PRISMA extension statement for reporting of systematic reviews incorporating network meta-analyses of health care interventions: checklist and explanations. Ann Intern Med. (2015) 162:777-84. doi: 10.7326/M14-2385

12. Chmura Kraemer H, Periyakoil VS, Noda A. Kappa coefficients in medical research. Stat Med. (2002) 21:2109-29. doi: 10.1002/sim.1180

13. Tierney JF, Stewart LA, Ghersi D, Burdett S, Sydes MR. Practical methods for incorporating summary time-to-event data into meta-analysis. Trials. (2007) 8:16. doi: 10.1186/1745-6215-8-16

14. Parmar MK, Torri V, Stewart L. Extracting summary statistics to perform meta-analyses of the published literature for survival endpoints. Stat Med. (1998) 17:2815-34. doi: 10.1002/(SICI)10970258(19981230)17:24<2815::AID-SIM110>3.0.CO;2-8

15. Higgins JP, Altman DG, Gotzsche PC, Juni P, Moher D, Oxman AD, et al. The Cochrane Collaboration's tool for assessing risk of bias in randomised trials. BMJ. (2011) 343:d5928. doi: 10.1136/bmj.d5928

16. Sterne JA, Hernan MA, Reeves BC, Savovic J, Berkman ND, Viswanathan M, et al. ROBINS-I: a tool for assessing risk of bias in non-randomised studies of interventions. BMJ. (2016) 355:i4919. doi: 10.1136/bmj.i4919

17. Stang A. Critical evaluation of the Newcastle-Ottawa scale for the assessment of the quality of nonrandomized studies in meta-analyses. Eur J Epidemiol. (2010) 25:603-5. doi: 10.1007/s10654-010-9491-z

18. Swiglo BA, Murad MH, Schünemann HJ, Kunz R, Vigersky RA, Guyatt GH, et al. A case for clarity, consistency, and helpfulness: state-of-the-art clinical practice guidelines in endocrinology using the grading of recommendations, assessment, development, and evaluation system. J Clin Endocrinol Metab. (2008) 93:666-73. doi: 10.1210/jc.2007-1907

19. Bowden J, Tierney JF, Copas AJ, Burdett S. Quantifying, displaying and accounting for heterogeneity in the meta-analysis of RCTs using standard and generalised Q statistics. BMC Med Res Methodol. (2011) 11:41. doi: 10.1186/1471-2288-11-41

20. Higgins JP, Thompson SG. Quantifying heterogeneity in a meta-analysis. Stat Med. (2002) 21:1539-58. doi: 10.1002/sim.1186

21. Singh A, Hussain S, Najmi AK. Number of studies, heterogeneity, generalisability, and the choice of method for meta-analysis. J Neurol Sci. (2017) 381:347. doi: 10.1016/j.jns.2017.09.026

22. Jansen JP, Cope S. Meta-regression models to address heterogeneity and inconsistency in network meta-analysis of survival outcomes. BMC Med Res Methodol. (2012) 12:152. doi: 10.1186/1471-2288-12-152

23. Higgins JP, Jackson D, Barrett JK, Lu G, Ades AE, White IR. Consistency and inconsistency in network meta-analysis: concepts and models for multi-arm studies. Res Synth Methods. (2012) 3:98-110. doi: 10.1002/jrsm.1044

24. Caldwell DM, Ades AE, Higgins JP. Simultaneous comparison of multiple treatments: combining direct and indirect evidence. Bmj. (2005) 331:897900. doi: 10.1136/bmj.331.7521.897

25. Mavridis D, Salanti G. A practical introduction to multivariate meta-analysis. Stat Methods Med Res. (2013) 22:133-58. doi: 10.1177/0962280211432219

26. Neoptolemos JP, Moore MJ, Cox TF, Valle JW, Palmer DH, McDonald $\mathrm{AC}$, et al. Effect of adjuvant chemotherapy with fluorouracil plus folinic acid or gemcitabine vs observation on survival in patients with resected periampullary adenocarcinoma: the ESPAC-3 periampullary cancer randomized trial. JAMA. (2012) 308:147-56. doi: 10.1001/jama.2012.14674

27. Takada T, Amano H, Yasuda H, Nimura Y, Matsushiro T, Kato H, et al. Is postoperative adjuvant chemotherapy useful for gallbladder carcinoma? A phase III multicenter prospective randomized controlled trial in patients with resected pancreaticobiliary carcinoma. Cancer. (2002) 95:168595. doi: 10.1002/cncr.10831

28. Leng KM, Liu YP, Wang ZD, Zhong XY, Liao GQ, Kang PC, et al. Results of adjuvant radiation therapy for locoregional perihilar cholangiocarcinoma after curative intent resection. Onco Targets Ther. (2017) 10:225766. doi: 10.2147/OTT.S131873

29. Mizuno T, Ebata T, Yokoyama Y, Igami T, Sugawara G, Yamaguchi $\mathrm{J}$, et al. Adjuvant gemcitabine monotherapy for resectable perihilar cholangiocarcinoma with lymph node involvement: a propensity score matching analysis. Surg Today. (2017) 47:182-92. doi: 10.1007/s00595-016-1354-0

30. Dover LL, Oster RA, McDonald AM, DuBay DA, Wang TN, Jacob R. Impact of adjuvant chemoradiation on survival in patients with resectable cholangiocarcinoma. HPB (Oxford). (2016) 18:843-50. doi: 10.1016/j.hpb.2016.07.008

31. Go SI, Kim YS, Hwang IG, Kim EY, Oh SY, Ji JH, et al. Is there a role for adjuvant therapy in R0 resected gallbladder cancer?: A propensity score-matched analysis. Cancer Res Treat. (2016) 48:127485. doi: $10.4143 / \mathrm{crt} .2015 .502$

32. Im JH, Seong J, Lee IJ, Park JS, Yoon DS, Kim KS, et al. Surgery alone versus surgery followed by chemotherapy and radiotherapy in resected extrahepatic bile duct cancer: treatment outcome analysis of 336 patients. Cancer Res Treat. (2016) 48:583-95. doi: 10.4143/crt.2015.091

33. Wang J, Narang AK, Sugar EA, Luber B, Rosati LM, Hsu CC, et al. Evaluation of adjuvant radiation therapy for resected gallbladder carcinoma: a multi-institutional experience. Ann Surg Oncol. (2015) 22 Suppl 3:S11006. doi: 10.1245/s10434-015-4685-y

34. Toyoki Y, Ishido K, Kudo D, Kimura N, Hakamada K. Adjuvant chemotherapy using s-1 improves survival in patients with resected advanced extra-hepatic bile duct cancer: A propensity score matching analysis. Journal of Clinical Oncology. (2015) 33:e15170-e. doi: 10.1200/jco.2015.33.15_suppl.e15170

35. Hoehn RS, Wima K, Ertel AE, Meier A, Ahmad SA, Shah SA, et al. Adjuvant chemotherapy and radiation therapy is associated with improved survival for patients with extrahepatic cholangiocarcinoma. Ann Surg Oncol. (2015) 22 Suppl 3:S1133-9. doi: 10.1245/s10434-015-4599-8

36. Hyder O, Dodson RM, Sachs T, Weiss M, Mayo SC, Choti MA, et al. Impact of adjuvant external beam radiotherapy on survival in surgically resected gallbladder adenocarcinoma: a propensity score-matched Surveillance, Epidemiology, and End Results analysis. Surgery. (2014) 155:8593. doi: 10.1016/j.surg.2013.06.001

37. Narang AK, Miller RC, Hsu CC, Bhatia S, Pawlik TM, Laheru D, et al. Evaluation of adjuvant chemoradiation therapy for ampullary adenocarcinoma: the Johns Hopkins Hospital - Mayo Clinic collaborative study. Radiation Oncology. (2011) 6:126. doi: 10.1186/1748-717X-6-126

38. Kim TH, Han SS, Park SJ, Lee WJ, Woo SM, Moon SH, et al. Role of adjuvant chemoradiotherapy for resected extrahepatic biliary tract cancer. Int J Radiat Oncol Biol Phys. (2011) 81:e853-9. doi: 10.1016/j.ijrobp.2010.12.019

39. Murakami Y, Uemura K, Sudo T, Hashimoto Y, Nakashima A, Kondo $\mathrm{N}$, et al. Prognostic factors after surgical resection for intrahepatic, hilar, and distal cholangiocarcinoma. Ann Surg Oncol. (2011) 18:6518. doi: 10.1245/s10434-010-1325-4

40. Gold DG, Miller RC, Haddock MG, Gunderson LL, Quevedo F, Donohue JH, et al. Adjuvant therapy for gallbladder carcinoma: the Mayo Clinic Experience. Int J Radiat Oncol Biol Phys. (2009) 75:150-5. doi: 10.1016/j.ijrobp.2008.10.052

41. Murakami Y, Uemura K, Sudo T, Hayashidani Y, Hashimoto Y, Nakamura H, et al. Adjuvant gemcitabine plus S-1 chemotherapy improves survival after aggressive surgical resection for advanced biliary carcinoma. Ann Surg. (2009) 250:950-6. doi: 10.1097/SLA.0b013e3181b0fc8b

42. Borghero Y, Crane CH, Szklaruk J, Oyarzo M, Curley S, Pisters PW, et al. Extrahepatic bile duct adenocarcinoma: patients at high-risk for local recurrence treated with surgery and adjuvant chemoradiation have an equivalent overall survival to patients with standard-risk treated with surgery alone. Ann Surg Oncol. (2008) 15:3147-56. doi: 10.1245/s10434-008-9998-7

43. Hughes MA, Frassica DA, Yeo CJ, Riall TS, Lillemoe KD, Cameron JL, et al. Adjuvant concurrent chemoradiation for adenocarcinoma of the distal common bile duct. Int J Radiat Oncol Biol Phys. (2007) 68:17882. doi: 10.1016/j.ijrobp.2006.11.048

44. Sikora SS, Balachandran P, Dimri K, Rastogi N, Kumar A, Saxena R, et al. Adjuvant chemo-radiotherapy in ampullary cancers. Eur J Surg Oncol. (2005) 31:158-63. doi: 10.1016/j.ejso.2004.08.013 
45. Vitale A, Moustafa M, Spolverato G, Gani F, Cillo U, Pawlik TM. Defining the possible therapeutic benefit of lymphadenectomy among patients undergoing hepatic resection for intrahepatic cholangiocarcinoma. J Surg Oncol. (2016) 113:685-91. doi: 10.1002/jso.24213

46. Spolverato G, Vitale A, Cucchetti A, Popescu I, Marques HP, Aldrighetti L, et al. Can hepatic resection provide a long-term cure for patients with intrahepatic cholangiocarcinoma? Cancer. (2015) 121:3998-4006. doi: 10.1002/cncr.29619

47. Yeh CN, Hsieh FJ, Chiang KC, Chen JS, Yeh TS, Jan YY, et al. Clinical effect of a positive surgical margin after hepatectomy on survival of patients with intrahepatic cholangiocarcinoma. Drug Des Devel Ther. (2015) 9:16374. doi: 10.2147/DDDT.S74940

48. Weber SM, Jarnagin WR, Klimstra D, DeMatteo RP, Fong Y, Blumgart LH. Intrahepatic cholangiocarcinoma: resectability, recurrence pattern, and outcomes. J Am Coll Surg. (2001) 193:384-91. doi: 10.1016/S1072-7515(01)01016-X

49. Ghidini M, Tomasello G, Botticelli A, Barni S, Zabbialini G, Seghezzi $S$, et al. Adjuvant chemotherapy for resected biliary tract cancers: a systematic review and meta-analysis. HPB (Oxford). (2017) 19:7418. doi: 10.1016/j.hpb.2017.05.010

50. Stein A, Arnold D, Bridgewater J, Goldstein D, Jensen LH, Klümpen HJ, et al. Adjuvant chemotherapy with gemcitabine and cisplatin compared to observation after curative intent resection ofcholangiocarcinoma and muscle invasive gallbladder carcinoma (ACTICCA-1 trial) - a randomized, multidisciplinary, multinational phase III trial. BMC Cancer. (2015) 15:564. doi: 10.1186/s12885-015-1498-0

51. Woods BS, Hawkins N, Scott DA. Network meta-analysis on the loghazard scale, combining count and hazard ratio statistics accounting for multi-arm trials: a tutorial. BMC Med Res Methodol. (2010) 10:54. doi: 10.1186/1471-2288-10-54

52. Ades AE, Sculpher M, Sutton A, Abrams K, Cooper N, Welton $\mathrm{N}$, et al. Bayesian methods for evidence synthesis in cost-effectiveness analysis. Pharmacoeconomics. (2006) 24:1-19. doi: 10.2165/00019053-200624010-00001

Conflict of Interest: The authors declare that the research was conducted in the absence of any commercial or financial relationships that could be construed as a potential conflict of interest.

Copyright (c) 2021 Chen, Meng, Xiong and Zou. This is an open-access article distributed under the terms of the Creative Commons Attribution License (CC BY). The use, distribution or reproduction in other forums is permitted, provided the original author(s) and the copyright owner(s) are credited and that the original publication in this journal is cited, in accordance with accepted academic practice. No use, distribution or reproduction is permitted which does not comply with these terms. 